\title{
LYRASIS Research and an Inclusive Approach to Open Access in the United States
}

\section{Hannah Rosen}

LYRASIS, Atlanta, Georgia, USA

hannah.rosen@lyrasis.org, orcid.org/0000-0001-6804-7073

\section{Celeste Feather}

LYRASIS, Atlanta, Georgia, USA

celeste.feather@lyrasis.org, orcid.org/0000-0002-5907-7606

\section{Jill Grogg}

LYRASIS, Atlanta, Georgia, USA

jill.grogg@lyrasis.org, orcid.org/0000-0001-5136-4507

\section{Sharla Lair}

LYRASIS, Atlanta, Georgia, USA

sharla.lair@lyrasis.org, orcid.org/0000-0003-4847-0469

\begin{abstract}
In 2020, LYRASIS Research conducted a member survey of predominantly United States (U.S.) higher education libraries to understand the spectrum of attitudes and actions related to Open Access (OA). The results indicated that the U.S. approach to OA is decentralised, lacking the focused trends that are apparent in other areas of the world. The diversity among types
\end{abstract}


of colleges and universities in the U.S. is revealed through discussions about support or lack thereof for APCs, crowdfunding models, preprint repositories, the Subscribe to Open approach, and more. The array of OA approaches that garner support in the U.S. may appear confusing as we strive for scale in our efforts. LYRASIS has used its research findings, in combination with our deep understanding of U.S. higher education libraries, to develop a collaborative approach towards OA that provides multiple incentives and opportunities for libraries serving all types of institutions to engage. This article, expanding on the LIBER 2021 Conference Presentation of the same name, will outline the results of the survey, the conclusions LYRASIS has drawn, and our work to develop an inclusive approach to a variety of OA initiatives. Our understanding of the landscape of U.S. higher education has led us to develop or support several significant recent OA initiatives, including a fund for OA ebooks focused on United Nations Sustainable Development Goals topics and the establishment of the LYRASIS Open Access Community Investment Program (OACIP).

Keywords: Open Access; United States; LYRASIS; Publishing Models

\section{Introduction}

The Open Access (OA) landscape within the United States (U.S.) can be difficult to grasp due to the dizzying diversity of institution types participating in the scholarly communication environment. The U.S. higher education system includes over 4,000 institutions providing technical and career training, two-year Associate degrees, four-year baccalaureate degrees, and a variety of higher-level master, doctoral, and professional degrees (Digest of Education Statistics, 2017). Some are supported by state and local government funds from taxpayers, and the rest are privately owned with either a non-profit tax-exempt status or a commercial for-profit tax status. Numerous smaller four-year institutions have historical roots in religious communities. Each of these institutions has their own academic and financial pressures both from within and outside of the library, not to mention their own philosophical attitudes towards Open Access based on their institutional culture. This paper will first attempt to summarise and contextualise OA trends within the U.S., based on research performed at LYRASIS, a library consortium whose membership spans all U.S. geographic regions. 
This research has helped to catalyse the LYRASIS approach to OA, establishing a philosophy based on purposefully embracing a diversity of OA models and initiatives. In order to engage the largest possible number of US higher education libraries in support of $\mathrm{OA}$, new models to transform scholarly communication must provide affordability and local impact to a great diversity of institutions with respect to degree programs, student population size, and varying levels of focus on teaching and research. Models that support the diversity of participating institutions and encourage equity and inclusion are needed to encourage a wider participation in the movement to increase OA content. This paper will conclude with examining successful strategies based on research to encourage library OA participation in the U.S.

\section{About LYRASIS}

LYRASIS is a nationwide consortium based in the United States. We are not the national consortium, because such a thing does not exist within the U.S., but we do have a wide reach, serving over 1,000 predominantly academic libraries, as well as archives and museums. While we provide many different services, including open source software hosting, consulting and professional development, one of the oldest and core programs within LYRASIS is, like our European counterparts, licensing and negotiation for electronic resources on behalf of our libraries.

\section{U.S. Academic Landscape and Library Spending}

At the moment, support for all paywalled scholarly content models and programs largely comes from the institutions with four-year and higher level degree programs, a percentage which LYRASIS has seen reflected in OA spending through our partnerships. Chart 1 demonstrates that the number of institutions supporting doctoral degree programs represents roughly a quarter of all four-year and graduate institutions.

However, the proportion of funding in these two categories for library materials and services is essentially flipped, as shown in Chart 2. 
Chart 1: U.S. Four-Year and Graduate Institutions: Highest Level of Degree Granted (Indiana University Center for Postsecondary Research, 2018).

\section{U.S. Four-Year and Graduate Institutions:}

Highest Level of Degree Granted

The Carnegie Classifications of Higher Education 2018

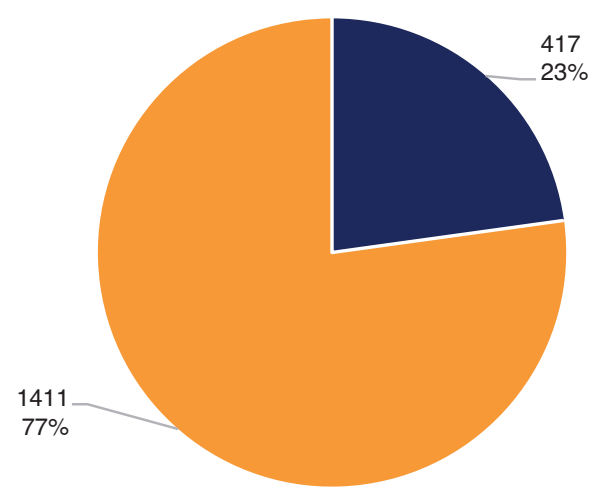

Doctoral Baccalaureate and Master

Chart 2: Library Materials and Services Expenditures, USD, Fiscal Year 2019 (IPEDS, 2019).

\section{Library Materials and Services \\ Expenditures, USD, Fiscal Year 2019 \\ National Center for Education Statistics, Integrated Post- \\ Secondary Education Data System}

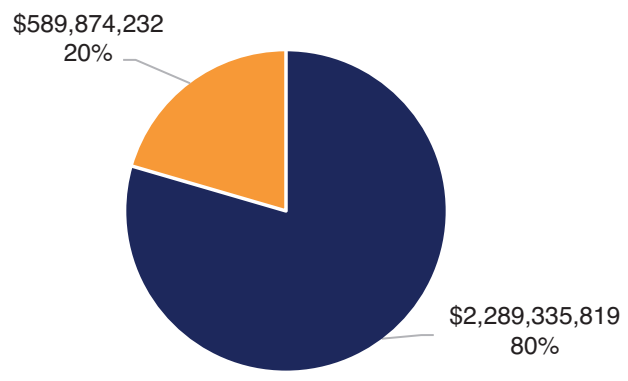

- Doctoral Baccalaureate and Master 
Chart 3: Student Headcount, Fiscal Year 2019 (IPEDS, 2019).

\section{Student Headcount, Fiscal Year 2019}

National Center for Educational Statistics,

Integrated Post-Secondary Education Data System

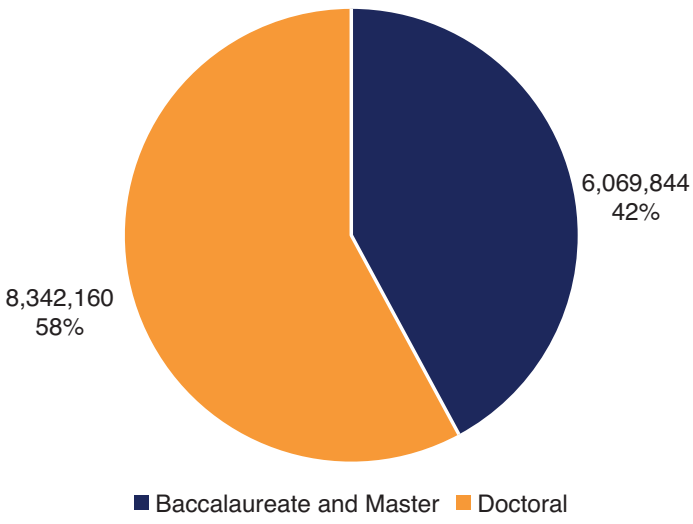

To add to the complexity, in terms of headcount as demonstrated in Chart 3, doctoral universities enroll a little less than $60 \%$ of all U.S. students getting baccalaureate degrees or higher.

This hints at a deeper issue: only a quarter of institutions are paying for OA on behalf of $60 \%$ of students, demonstrating a major imbalance in support of OA programs.

The cost cannot and should not be borne by doctoral institutions alone, even though they hold the majority of library collection budget dollars. Based on the statistics as seen in the previous charts, the US higher education space is dominated by those offering master and baccalaureate degrees. Yet robust participation by the doctoral institutions is essential for most OA programs to succeed. The benefits of OA accrue to all students wherever they are enrolled, as the published content supports the teaching programs of all institutions and therefore has the potential to lower the cost of acquiring a four-year or advanced degree. 


\section{LYRASIS OA Foundations}

Our work at LYRASIS with Open Access programs began in 2012 with the first phase of the SCOAP3 program for Open Access journal articles in high energy physics (LYRASIS, 2021a). Over the past eight years, we have continued to add new (predominantly European) Open Access programs into the content portfolio, including Open Library of Humanities, Reveal Digital, and Knowledge Unlatched. These offers are made available to the LYRASIS member community of over 1,000 libraries. Due to our administrative capabilities, we also frequently serve as the national U.S. contact point for certain OA programs, and therefore reach beyond our association's members to serve the entire US higher education community.

Although diverse, the OA programs that were supported at LYRASIS leading up to the pandemic (and, as will be discussed later, since then) have at least one thing in common: no article processing charges (APCs) are required to publish. These programs are largely dependent on crowdfunding from multiple stakeholder communities that include libraries, or a redirection of former paywalled subscription fees. While avoiding APCs was not a direct goal, due to LYRASIS' membership size and geographic scope, negotiating on behalf of groups of universities and authors felt unwieldy and beyond our organisational mission.

At the beginning of the COVID-19 pandemic in spring of 2020, the OA movement received a lot of attention when publishers, under pressure from both libraries struggling to give students remote digital access to assigned materials and non-profit funders such as the Wellcome Trust advocating for open access of COVID-19 materials to assist with research for cures and treatments (Wellcome, 2020), voluntarily opened their paywalled content packages for a limited period of time. This helped higher education libraries deliver digital content to their faculty and students when they were not able to physically be on campus or inside a library building. The merits of having expansive and unfettered access to more digital content became very apparent.

This temporary paywall departure looked to us to be an inflection point in US library attitudes towards OA, but we were not sure how that would affect our work supporting new and existing OA programs - we knew what some institutions were financially supporting, based on their contributions to LYRASIS programs, but we did not have any hard data surrounding their overall 
attitudes towards, and activities within, the open landscape. Serendipitously, in the fall of 2019 we had begun designing a survey to better understand our members' interaction with open content. The next section will detail our relevant findings from the report, as well as the conclusions we drew for our own strategic planning.

\section{LYRASIS 2020 Open Content Survey Report (Rosen \& Grogg, 2020)}

As mentioned in the introduction, due to the diversity of higher education institutions within the U.S., it was crucial to design a survey that was inclusive in its language, making sure not to discourage participants who were not familiar with the panoply of definitions surrounding open, such as Green/ Gold/Platinum OA, etc. For the purposes of the survey results and analysis, "open content" was defined as "information that can be read or accessed without any barriers, be they paywalls or institutional logins." The survey gathered data about how libraries are interacting with open content in three broad areas: OA scholarship, open data, and Open Educational Resources (OERs). This article will focus mainly on the OA scholarship portion of the survey - the survey defined OA scholarship as "any works written by scholars, academic faculty, or graduate students, covering, but not limited to, common formats such as theses, dissertations, journal articles, monographs, and preprints."

The survey was conducted between January 31 and March 22, 2020. It was distributed via two listservs run and maintained by LYRASIS staff and sent to additional targeted groups within the LYRASIS membership - approximately 2,000 contacts. One hundred and sixty-six (166) responses were used in the survey analysis. Over $70 \%$ of the respondents came from academic institutions, mostly from acquisitions and OA librarians. In total, $7 \%$ of respondents represented associate's colleges, 13\% represented baccalaureate colleges, $16 \%$ of respondents represented master's colleges and universities, and 36\% of respondents represented doctoral universities (the remaining $28 \%$ represented non-academic institutions). The survey does skew towards larger universities - however, we believe we received sufficient participation from small, medium and large institutions to make conclusions concerning nationwide trends. 
Chart 4: Does Your Library Have an Open Content Policy? All Responses.

Does your library have an open content policy? all individual responses

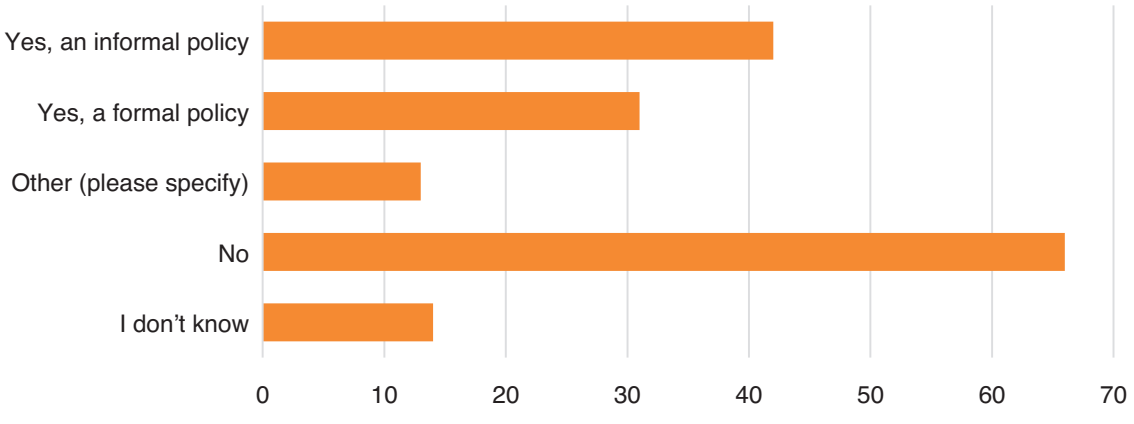

First, institutions were asked if they have any sort of open content policy ("e.g. any kind of policy regarding providing free access to campus faculty publications or data, financially supporting open publishers, publishing open journals, monographs, or educational resources, or any other form of support for free and open access to information"), the results of which are displayed in Chart 4.

Twenty-five percent (25\%) of respondents said they had an informal policy, and $24 \%$ of respondents said they had a formal policy - meaning roughly half of respondents have some form of policy, and only about a quarter of respondents have any formal documentation concerning open content. This information indicates that the majority of U.S. institutions are still trying to define open in terms of their institutions and institutional participation. ${ }^{1}$ Our team took this as an indicator that our deliberate participation in certain open activities would be highly impactful in influencing institution decision making.

More interesting is Chart 5, demonstrating the responses to questions related to financial support for OA initiatives outside of the institution.

Fifty-three percent (53\%) of respondents said they do not financially support outside initiatives, while 30\% do support outside initiatives. Fourteen percent $(14 \%)$ said they did not know, while 3\% said 'Other.' Of those that said 'Other,' a pattern emerged of supporting outside initiatives indirectly through membership in organisations such as HathiTrust, SPARC, or other library consortia. 
Chart 5: Does your library financially support outside OA initiatives - Total Percentage.

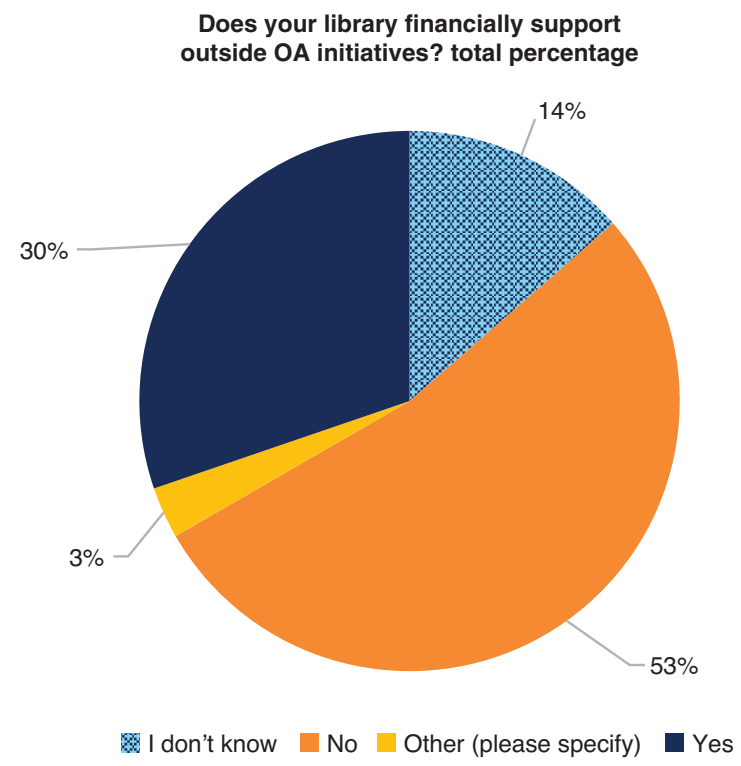

Institutions were also asked questions about their interaction with article processing charges (APCs) and book processing charges (BPCs). The APC fee structure is very widely adopted within European countries, and is often linked to national funding mandates and/or "transformative agreements" between single countries and major publishers. While there have been a handful of transformative agreements to come out of the United States (the most well-known being between the California Digital Library and Elsevier), the number of APC-based agreements has been relatively small compared to our European counterparts. Therefore we were interested in understanding how APC participation translated into the U.S. - specifically if there was a preference for what kinds of publishers received APC support. Libraries were asked, "Does your library provide financial support for APCs only for fully open publishers, or for hybrid publishers as well?" Responses can be seen below in Table 1.

It was notable that libraries, rather than showing strong preferences for fully OA vs hybrid journals, preferred not to interact with APCs at all, in direct 
Table 1: Does your library provide financial support for APCs only for fully open publishers, or for hybrid publishers as well?

\begin{tabular}{lllll}
\hline & $\begin{array}{l}\text { APCs for full } \\
\text { open only }\end{array}$ & $\begin{array}{l}\text { APCs for fully } \\
\text { open and hybrid }\end{array}$ & $\begin{array}{l}\text { No } \\
\text { APCs }\end{array}$ & $\begin{array}{l}\text { Other (please } \\
\text { specify) }\end{array}$ \\
\hline $\begin{array}{l}\text { Total Count } \\
\begin{array}{l}\text { Percentage (of those who said they } \\
\text { support outside OA initiatives) }\end{array}\end{array}$ & $11 \%$ & 7 & 24 & 9 \\
\hline
\end{tabular}

opposition to European trends. This confirmed a hunch we had based on looking at the national landscape: there are too many U.S. institutions that cannot and/or are not able to pursue APCs as a viable option. The smaller institutions that do not have publishing faculty receive no benefit from pursuing APC based agreements. These institutions do not have the fiscal, or perhaps more importantly, the administrative capacity to support APC based agreements, and are more inclined to support non-APC initiatives. This showed us that our dedication to non-APC initiatives was vindicated by national preferences, and it should be something that we continued to pursue.

We then asked our members what kinds of OA initiatives they did financially support, to see if there were any overarching trends. Of those respondents who did financially support Open Access activities (as a reminder, this was roughly $30 \%$ ), the predominant trend was an embrace of diverse models: $65 \%$ of active supporters financially contribute to non-APC monograph initiatives, such as Knowledge Unlatched and support non-APC journal initiatives such as the Open Library of the Humanities, while 56\% supporters contribute to outside repositories such as ArXiv and PubMed Central. We were able to extrapolate from this data to presume that for those libraries that support OA Publishing, the majority support multiple types of initiatives - no one model or type of material appears to be dominant. Instead, we presume libraries are focusing on supporting initiatives based on content and relevance to their institution. Therefore we took it upon ourselves to support a varied portfolio of publishers highlighting a diversity of content. We also took both of these conclusions as a sign that we needed to continue to pursue a diversity of models, knowing that many of our members already comfortably support a plethora of non-APC initiatives. The next section will outline the new initiatives we pursued during the pandemic based on conclusions from the Open Content Survey. 


\section{Pandemic OA Initiatives}

In the past year there has been a noticeable increase in the number of both new and more established OA programs seeking ongoing sustainability that have initiated conversation with LYRASIS. All new programs that LYRASIS has introduced are brought to libraries after careful evaluation, based on conclusions from our survey - a continued support of non-APC based initiatives, as well as an embrace of multiple types of publishers and models. With every opportunity we are planning ways to incentivise, encourage, include, and engage libraries across the spectrum of US higher education.

The programs we support are, we believe, trying to build more equitable and inclusive funding models and infrastructures that operationalise and normalise this new way of investing in scholarly publishing. These programs, such as the Central European Press Opening the Future initiative use existing and/or experimental collective funding models, such as crowdfunding campaigns and membership programs, to collect sustainable levels of revenue that cover their costs. Many of them distribute the costs across the funding communities they are trying to build through the strategic design of pricing tiers that contain low price points allowing for easy entry points for all types and sizes of stakeholders and their budgets to participate.

While LYRASIS has embarked on several new partnerships to help support journal and monograph publishers, as well as open infrastructure, this next section will provide an overview of the two major new OA programs that LYRASIS helped initiate during the pandemic.

\subsection{Open Access Community Investment Program (LYRASIS \& TSPOA, 2021)}

In the emerging OA publishing space, the library community, along with any other research or academic unit considering how to support open access, are all confronted with opportunities to invest in thousands of OA publications. But libraries do not always have sufficient information about those publications or projects to vet them and make an informed investment decision relative and relevant to their institutional values. As has been mentioned in earlier sections of this article, libraries also often lack the administrative capabilities necessary to manage publications transitioning to OA. 
In response to this need, LYRASIS and Transitioning Society Publications to OA (TSPOA), in collaboration with a cadre of librarians and mission-aligned publishers, have developed a community-driven, single entry point that allows multiple stakeholders to vet and fund scalable OA content initiatives. We are calling it the Open Access Community Investment Program, or OACIP. Our primary aim was to develop a way to help match libraries and other prospective funders with non-profit publishers and journal editorial boards that are seeking financial investments to sustain or transition to open access publishing of journals or books. Collectively, we developed criteria that publishers have an opportunity to respond to in order to be selected to participate. The program seeks to find the right questions to ask of publishers and then provide those answers to potential investors so that they can evaluate the propriety of investment relative to how and whether the responses satisfy their investment values and principles. Finally, we needed a way to connect the community of potential investors to what we were creating, so we needed an infrastructure to aggregate the investment opportunities, along with outreach to promote it.

We launched the pilot of OACIP in December 2020 and it ran until the end of June 2021. We selected two Diamond $\mathrm{OA}^{2}$ journals to participate, Environmental Humanities (published by Duke University Press) and Combinatorial Theory (published on the University of California's eScholarship platform, managed by the California Digital Library). Then we built a no frills webpage on the LYRASIS website, and administered it efficiently with the idea that so long as we maintain a healthy ratio of resources in proportion to participating programs, we can grow the program sustainably as more resources become available. Thanks to library funders from the LYRASIS community, both journals met their fundraising goals to sustainably publish $\mathrm{OA}$, free to read and free to publish, for the next five years.

We believe that OACIP has the potential to provide a more effective funding infrastructure to sustainably transition scholarly publishing to OA, and we are currently building on the pilot's success by launching a second round of journals in need of investment.

\subsection{The LYRASIS United Nations Sustainable Development Goals (UNSDG) Fund (LYRASIS, 2021b)}

Along with partnering with non-profit OA publishers, LYRASIS sought creative ways to engage its diverse existing subscriber communities of paywalled 
content. When LYRASIS holistically assessed its subscriber communities, large journal groups emerged as a possibility for expanded OA engagement as such groups present an opportunity to re-imagine negotiations to achieve transformative agreements. Transformative or transitional agreements seek to build a bridge across the licensing chasm between traditional, paywalled content and support for OA publishing. To date, success with transformative agreements with large, established publishing houses, are predominantly based on APCs, which are not feasible for all institutions in a given LYRASIS journal group. LYRASIS' journal groups represent a spectrum that extends from "read" to "publish" institutions, e.g., those institutions who purchase journal content but are less likely to have large faculty populations who publish to those institutions who both purchase journal content and also publish significant amounts of research, respectively.

In order to apply the lessons of the Open Content Survey Report to OA activities within our journal groups, we wanted to expand the current understanding of a transformative agreement beyond APC considerations and eliminate minimum thresholds for participation.

In 2020, the LYRASIS Springer Nature Journals Group was nearing the end of its five-year deal, which originally spanned 2017-2021. We had intended to reevaluate this contract in terms of cost versus content in preparation for the next iteration of negotiations, but the pandemic hastened our timeline. The LYRASIS Springer Nature Journals Group exemplifies LYRASIS membership as a whole: a diverse group of institutions across the "read" /"publish" spectrum. This subscriber group presented an ideal opportunity to meet our goals due to Springer Nature's robust commitment to publishing content that supports the United Nations Sustainable Development Goals (UNSDGs) (Springer Nature, 2021).

Working with Springer Nature and the diverse institutions in the LYRASIS Springer Nature Journals Group, we were able to re-negotiate lower subscription costs for a new multi-year contract and simultaneously redirect the savings toward OA SDG-aligned content. We created the LYRASIS United Nations Sustainable Development Goals Fund (LYRASIS, 2021b) to crowdsource the publication of OA ebooks that support the UN SDGs. There was no minimum threshold for participation, and thirty-one (31) institutions of all sizes and budgets re-directed their cost savings from the renegotiated contract to the collective fund. LYRASIS worked with institutional contributors and Springer Nature to identify ebooks that specifically appeal to 
undergraduate-level teaching, which spans the "read"/"publish" mission spectrum: as of September 2021, five (5) ebooks will be made OA as a result of our negotiations.

During its initial phase the LYRASIS UNSDG Fund is centered around OA ebooks published by Springer Nature, but we are diligently working to expand our efforts to include other publishers who have signed the UN SDG Publisher Compact (United Nations, 2021) as well as other LYRASIS members who are not part of the LYRASIS Springer Nature Journals Group.

\section{Library Reactions}

Incentives to support OA in the United States are varied. The most common ones mentioned by higher education libraries include lowering the barriers to publish, decreasing the cost of publishing, making more content available to support teaching, and altruism for the sake of openly sharing knowledge with the wider community. Unlike in other parts of the world, there is rarely discussion among US librarians about potential economic benefits to the country as a result of openly sharing scholarly communications from the higher education research community.

A key part of the challenge facing the US higher education community is the development of a variety of incentives that will spur libraries to invest in OA. Campus administrators require rationale and justification to support OA, particularly at state supported public institutions where there are challenges around spending taxpayer funds to support the creation of content that others outside the state can use without providing similar financial support.

Despite these challenges, since the start of the pandemic the level of enthusiasm for new scholarly content programs by the US higher education library community seems to have increased for OA programs and decreased for new paywalled products. Anecdotally, we are finding that it is now much easier to engage a group of interested librarians in conversation around support for OA than it is to gather an interested group to discuss a new paywalled collection of content. The rate of pledges to support OA programs increases each year as a proportion of the total number of orders/pledges that LYRASIS invoices to libraries for scholarly content. 
When looking at the many initiatives we have introduced at LYRASIS, we have seen encouraging signs of increasing support for OA. LYRASIS has worked with more institutions that are stepping forward to offer meaningful support to the growing number of initiatives that do not require payment from authors to publish. Since our work with Open Access programs began in 2012, there has been a 32\% increase in the number of libraries participating in these programs. However, as can be seen in Chart 6, this relatively slow growth has been bolstered by a $107 \%$ increase in the total number of times each year these libraries support an Open Access program at LYRASIS. These trends, viewable in Chart 6, show that once libraries engage with the crowdfunding or subscription fund redirection models, they are more likely to engage in additional ones as time passes and the models prove to be successful and sustainable.

The largest increase in the number of annual financial commitments came during fiscal year 2021, a growth by $22 \%$ over the number of commitments made in the previous year, during a global pandemic and a time of great financial upheaval.

At the present time, $43 \%$ of all US higher education institutions at the doctoral level are participating in OA programs through LYRASIS. While that number is encouraging, more work remains to be done. In comparison, as seen in Chart 7, only 7\% of all US higher education institutions offering master and baccalaureate degrees as their highest levels are participating in these same OA programs.

Chart 6: Count of Annual Financial Commitments to Support LYRASIS OA Programs, 2014-2021.

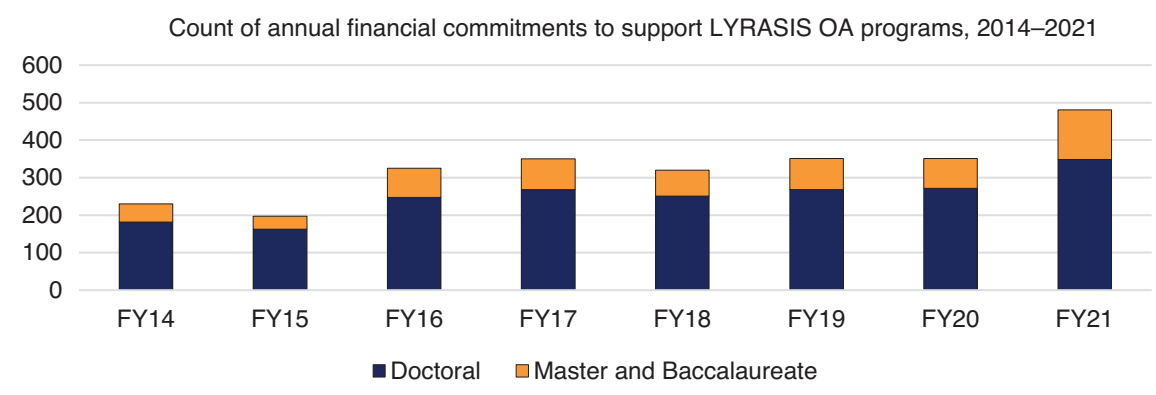


Chart 7: Percentage of U.S. Four-Year and Graduate Institutions Support OA Publishing Through LYRASIS, 2014-2021.

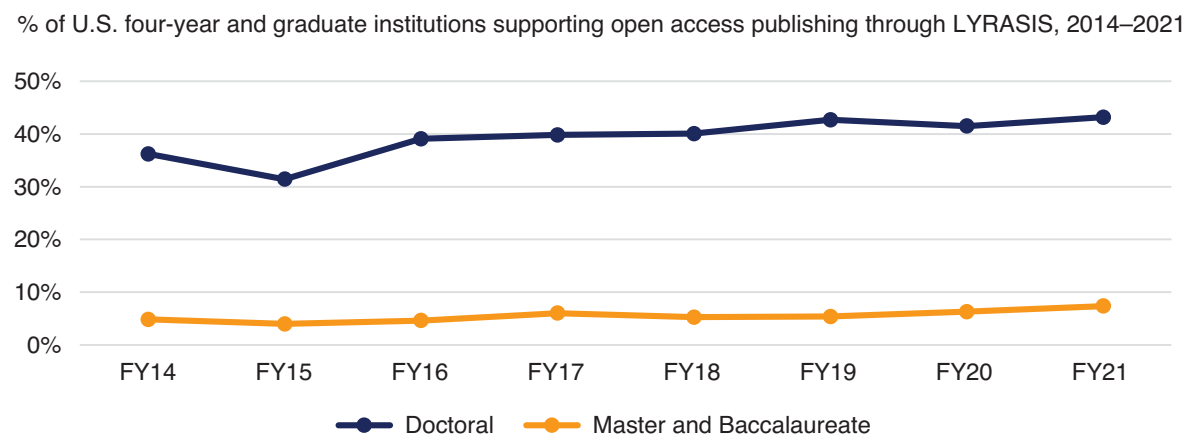

A great deal of additional work, model development, outreach, and education is needed in order to create opportunities, rationale, and incentives for these teaching-focused institutions to be able to provide more robust support for Open Access. Master and baccalaureate institutions in fiscal year 2021 contributed 3\% of the total funds gathered for Open Access programs through LYRASIS. As mentioned earlier, these institutions collectively hold around $20 \%$ of the library collection funds among US higher education institutions with four-year and/or graduate level degree programs. There are likely many reasons for this gap in funding, but it is clear that teaching institutions (master and baccalaureate programs) are not deliberately withholding funds in order to be "free-riders," using content paid for by other universities.

\section{Conclusion}

Based on all the data we have gathered, our conversations with librarians, and personal observations during the past year, there appears to have been a significant shift of interest toward the development of new OA models based on library cost-sharing and crowdfunding of new content. Publishers are more willing to engage in conversations and explore possibilities, and libraries seem to be taking a longer view of the scholarly communication ecosystem and placing more emphasis on socially responsible investment of the collection dollars that they steward for their campuses. There seems to be an increasing eagerness and receptivity across all the stakeholder communities 
to new ideas that embrace the concepts of meeting the needs of diverse participants and finding more collaborative pathways moving forward.

There is no one model for Open Access that works equally well across a diverse community. We must continue to develop new programs and models that engage teaching focused institutions if we want to fill important gaps in our work to transform scholarly communication. In order to maintain a healthy, balanced, U.S. higher educational ecosystem that serves the needs of all types of students, we need to develop and establish new frameworks that facilitate participation, not just observation, in the journey towards a different future that opens up more scholarly content to a world of users.

\section{References}

Digest of Education Statistics. (2017). Table 317.10. Degree-granting postsecondary institutions, by control and level of institution: Selected years, 1949-50 through 2016-17 [Data Set]. National Center for Education Statistics. https://nces.ed.gov/programs/ digest/d17/tables/dt17 317.10.asp?current=yes.

IPEDS. (2019). The Integrated Post Secondary Education Data System [Data Set]. National Center for Education Statistics. https://nces.ed.gov/ipeds/use-the-data.

Indiana University Center for Postsecondary Research (2018). Carnegie Classifications Data File Version 1b: December 20, 2018 [Data Set]. The Carnegie Classification of Institutions of Higher Education. https:// carnegieclassifications.iu.edu/downloads/ CCIHE2018-PublicData.xlsx.

LYRASIS. (2021a, September 24). SCOAP3. https://www.lyrasis.org/content/Pages/ Scoap3.aspx.

LYRASIS. (2021b, September 24). LYRASIS United Nations Sustainable Development Goals Fund. https://www.lyrasis.org/content/Pages/product-details.aspx?pid= 6D826BB2-7440-EB11-80ED-00155DE5EC03.

LYRASIS \& TSPOA. (2021, September 24). OACIP. https://www.lyrasis.org/content/ Pages/oacip.aspx.

Rosen, H., \& Grogg, J. (2020). LYRASIS 2020 Open Content Survey Report. LYRASIS. https://doi.org/10.48609/nwr2-9313.

Springer Nature. (2021, September 24). The Sustainable Development Goals Programme. https://www.springernature.com/gp/researchers/sdg-programme.

United Nations. (2021, September 24). SDG Publishers Compact. https://www.un.org/ sustainabledevelopment/sdg-publishers-compact/. 
Wellcome. (2020, January 31). Sharing research data and findings relevant to the novel coronavirus (COVID-19) outbreak. https://wellcome.org/press-release/ sharing-research-data-and-findings-relevant-novel-coronavirus-ncov-outbreak.

\section{Notes}

1 "[when looking at the breakdown of institution types] it becomes evident that associate's colleges are most likely to have little or no policy, while doctoral universities are most likely to have either formal or informal policies. Unsurprisingly, the larger the institution, the higher the percentage of libraries that have a formal policy. However, the results are more muddled in the middle - the master's institutions have a lower rate of informal policies than the baccalaureate colleges, and a higher rate had no policies."

${ }^{2}$ Diamond OA, referring to journals that do not require APCs to publish. 